\title{
The effects of temperature on the feeding performance of invasive fishes
}

\author{
Tyler J. Sloan*, Ralph G. Turingan \\ Biological Sciences, Florida Institute of Technology, Melbourne, FL, USA \\ Email address: \\ Tsloan2009@my.fit.edu (T. J. Sloan), Turingan@ fit.edu (R. G. Turingan)
}

To cite this article:

Tyler J. Sloan, Ralph G. Turingan. The Effects of Temperature on the Feeding Performance of Invasive Fishes. American Journal of Life Sciences. Vol. 2, No. 2, 2014, pp. 63-71. doi: 10.11648/j.ajls.20140202.15

\begin{abstract}
It has been hypothesized that the effects of the coupling of climate-change and invasive-species phenomena exceed the impact of each separately on ecosystem dynamics and stability. However, very few studies address the interaction between these two most alarming concerns of science and society. Using two Florida invasive fishes, Pteroisvolitansand Cichlasoma urophthalmus, this study attempts to address this synergy by providing empirical evidence that (1) demonstrates how the performance of invasive species responds to environmental-temperature change, and (2) enhances our understanding of the implications of species invasion in the light of the global-climate-change phenomenon. Kinematic analyses revealed the following results:(1) At a given temperature $\left(20^{\circ} \mathrm{C}, 25^{\circ} \mathrm{C}\right.$, and $\left.30^{\circ} \mathrm{C}\right)$ prey-capture kinematics differed between species;(2) Each species maintained similar excursion and timing kinematics throughout the range of water temperatures;(3) The temperature-independence of the average kinematic values is reinforced by the consistent kinematic profile throughout the temperature range. We propose that more research is needed to corroborate the plausible avenues where the interplay between climate-change and invasive-species phenomena may be demonstrated, including: (1) the temperature-induced effects on physiological and mechanical processes; (2) the likelihood that these physiological effects extend to whole-organism performance; and (3) the resilience of invasive species and their resistance of whole-organism performance to temperature change.
\end{abstract}

Keywords: Invasive Fishes, Climate Change, Environmental Temperature, Lionfish, Mayan Cichlid, Performance

\section{Introduction}

Scientists and society have always been concerned about the introduction and proliferation of exotic species in invaded ecosystems for well-known reasons. Among others, invasive species are vectors for diseases [1-3], change existing community structure [4-6]alter food webs [7-9], hybridize [10-12], and drive native species into extinction [9,13-14]. Our growing concern about the consequences of climate change, in general, and how global warming mediates the performance and spread of invasive species, in particular, underscores the need for contemporary research that addresses how the performance of invasive species is affected by environmental temperature [15-17]. Physiological processes such as metabolic rate, as well as contractile properties and mechanics of skeletal muscles are affected by body and environmental temperature [18-24]. For example, poikilotherms such as fishes swim and feed differently when subjected to varying levels of environmental temperature [21,25-31]. The majority, if not all of existing literature deal with issues of invasive species apart from climate change phenomenon. However, it has been hypothesized that the synergy between these two major ecological and societal concerns, i. e., climate change and invasive species, is more important than their individual contributions to global change [32,33]. In this study, we attempt to address this synergy by providing empirical evidence that (1) demonstrates how the performance of invasive species responds to environmental-temperature change, and (2) enhances our understanding of the implications of species invasion in the light of the global-climate-change phenomenon.

Kinematics is a prominent metric of whole-animal performance and has been used extensively in contemporary research that investigates the effects of environmental temperature on animal locomotion and to a much lesser extent, on feeding performance [26-30,34-36). In the North American native-fish species, bluegill (Lepomismacrochirus)[29] and largemouth bass, Micropterussalmoides [30] the timing of kinematic events 
during prey capture was slower in colder than in warmer water temperatures. In contrast, Sloan and Turingan [35] and Turingan and Sloan [36] concluded that the average magnitude of feeding-kinematic events in two Florida nonnative-fish species was not affected by environmental temperature. This study focuses on the kinematics of preycapture in lionfish, Pteroisvolitans and Mayan cichlid, Cichlasoma urophthalmus, two invasive Florida (USA) species with contrasting life-history and ecology. This comparison further elucidates the similarity or disparity of temperature response between marine- and freshwater- fish species[37-39].

The lionfish, Pteroisvolitans, is native to the Indo-Pacific Ocean[40,41]. It's introduction and rapid expansion in the Caribbean and along the Atlantic coast of the USA is perhaps one of the most alarming threats to the marine fauna of the region [42,43]. Invasive lionfish have been sighted as far south as Jamaica, as far north as Rhode Island, and as far northeast as Bermuda [40,44-46]. It is hypothesized that the initial source of introduction of lionfish into the Western Atlantic Ocean was through an aquarium-fish release in Biscayne Bay, Florida in 1992 $[41,46,47]$. Gut-content analyses of invasive lionfish have revealed that this fish feeds on a diverse group of native Atlantic coral reef fish species [42,46]. Also, Layman and Allgeier[48] found that invasive lionfish in the Bahamas, fed almost exclusively on small coral-reef fishes. A more comprehensive study of Bahamian lionfish diet by Morris and Atkins [42]revealed that by volumetric contribution, 78\% and $14 \%$ of their diet comprised of teleost fishes and crustaceans respectively. More interestingly, the teleost-fish diet included 21 families and 41 species of coral-reef fishes, providing empirical evidence of the ecological impact of this invasive piscivore. Piscivory is perhaps facilitated by a suction-feeding mechanism and characteristic rapid-strikes on more mobile, elusive prey. The lionfish modulates its suction-feeding performance when feeding on fish and crustacean prey [49].

The Mayan cichlid, Cichlasoma urophthalmus, is native to fresh- and brackish-waters of Mexico, the Yucatan Peninsula and Isla Mujeres, Belize, Guatemala, Honduras, and Nicaragua [50,51]. It is believed to have been introduced in the Everglades National Park, Florida (USA) in 1983 [52].Its range of invasive distribution in Florida extends as far north as Merritt Island on the east coast and Tampa area on the west coast [36,53].The invasive Mayan cichlid has a generalist diet compared to the piscivorous diet of the invasive lionfish; it feeds on detritus, plants, invertebrates and fish [52,54-57].Just like the generalized species in the family Cichlidae, the Mayan cichlid has an oral-jaw prey-capture mechanism and a well-developed pharyngeal-jaw apparatus for prey-processing that is characteristic of the family[58].

Both invasive lionfish and Mayan cichlid have continued to spread from the warmer waters of south Florida to the colder, northern regions of the state [53,59]. Along the east coast of Florida where the distribution of both invasive species overlap, the average annual water temperature ranges from $20^{\circ} \mathrm{C}$ to $30^{\circ} \mathrm{C}[60]$. The $10^{\circ} \mathrm{C}$-range of environmental temperature experienced by both invasive species provides a basis for the central question in this study, "How does feeding performance of these invasive species respond to environmental change?" The known effects of temperature on the physical properties of water that affect predator-prey interactions, and on the contractile properties of muscles that drive kinematics serve as the premise for testing three hypotheses: (1) At a given temperature, the prey-capture kinematics differ between both invasive fish species. (2) The prey-capture kinematics of each invasive fish species varies across environmental temperatures. (3) The kinematic profiles of each species will vary across temperature regimes.

\section{Materials and Methods}

Four $P$. volitanscollected from Sebastian Inlet and four $C$. urophthalmus, collected from Merritt Island, Florida were acclimated and trained for high-speed filming in the fish ecophysiology laboratory at Florida Institute of Technology. Each fish was housed in 381 filming tanks filled with $24 \mathrm{ppt}$ water, and then filmed at $20^{\circ} \mathrm{C}, 25^{\circ} \mathrm{C}$ and $30^{\circ} \mathrm{C}$. Temperature was raised from $20^{\circ} \mathrm{C}$ to the higher filming temperatures at a rate of $1^{\circ} \mathrm{C}$ daily using a water heater. Each fish was filmed using a Red Lake High-Speed Motionscope $2000 \mathrm{~S}$ camera with a shutter speed of $1 / 1000 \mathrm{~s}$ at 250 frames $\mathrm{s}^{-1}$ while feeding on live mosquito fish (Gambusiaholbrooki). Feeding sessions were recorded every other day and fish were not fed in between recording sessions in order to keep their motivation high, enabling them to execute maximum prey-capture performance during filming. At least four feeding bouts were recorded for each fish. Four films were analyzed per fish at each of the three experimental temperatures using MaxTRAQ (Version 2.2.4.1 Innovision Systems, Inc.).

Each film was played back frame-by-frame to measure eight kinematic variables used to compare prey-capture kinematics between the two nonnative species and among three temperature regimes. The four displacementkinematic variables are defined in Table 1 and Figure 1. Time to reach the maximum displacement-kinematic variables defined in Table 1 namely time (s) to maximum gape, hyoid depression, lower jaw angular displacement and cranial rotation were measured relative to the frame prior to mouth opening.

Table 1 shows definition and measurement of the excursion-kinematic variables used to examine variation in feeding performance between species and across temperatures. The timing variables for each of these maximum excursion variables were also calculated along with duration of feeding bout (s). Duration of feeding bout was defined as the time elapsed between the frame just before the initiation of mouth-opening and the frame at which the mouth fully closed after prey capture. These identified hotspots are illustrated in Figure 1. 
Table 1. Description of the method of measuring the excursion-kinematic variables; refer to Figure 1 for the hotspots referenced in the descriptions.

\begin{tabular}{ll}
\hline Kinematic Variable & Description \\
\hline Maximum Gape (mm) & $\begin{array}{l}\text { Maximum distance measured from the anteriormost tip of the premaxilla to the } \\
\text { anteriormost tip of the dentary when the mouth is open. Points (A) to (C). } \\
\text { Maximum Hyoid Depression (mm) } \\
\text { Maximum length measured from the center of the eye to the anteriormost point of } \\
\text { the mouth at full depression. Points (E) to (D). } \\
\text { Maximum Lower Jaw Angular Displacement (degree) } \\
\text { Maximum Cranial Rotation (degree) }\end{array}$ \\
$\begin{array}{l}\text { Maximum rotation of the lower jaw measured by the line segments AB to BC. } \\
\text { angle formed from line segments AG to GF. }\end{array}$ \\
\hline
\end{tabular}

Figure 1 shows representative frames at maximum kinematic excursion from a film of each fish capturing prey. Each frame identifies the hotspots used to measure the excursion-kinematic variables identified in Table 1 for lionfish (left panel) and Mayan cichlid(right panel).

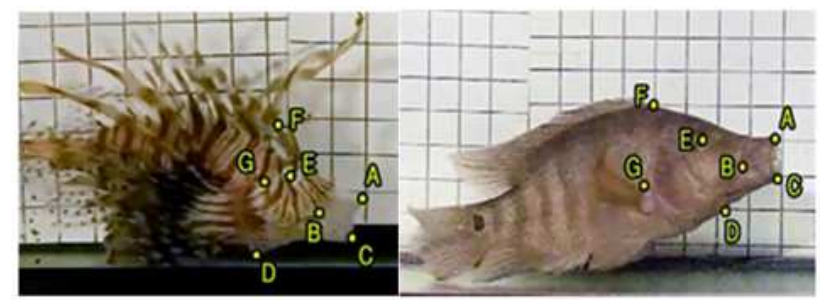

Figure 1. Representative frames for lionfish (left) and Mayan cichlid (right) showing the kinematic hotspotsidentified in Table 1.

To test the above-stated research hypotheses, the kinematic variables were $\log _{10}$-transformed and subjected to a 2-way Repeated Measures Multivariate Analysis of Covariance (MANCOVAR) with species and temperature as the main effects, the nine kinematic measurements as the dependent variables and fish standard length as the covariate. Previous studies on the kinematics of both species indicated that body size was correlated with kinematic variables, thus, an analysis of covariance was necessary to eliminate the confounding effects of body size on the results of the inter specific comparisons [35,36,57]. Kinematic profiles were produced from frame-by-frame analysis of the feeding films and recording the magnitude of the kinematic excursion at 3-millisecond intervals. Mean kinematic excursion at time intervals of the four fish per species was plotted against time, as shown in Figure 2.

\section{Results}

Regardless of temperature, once the prey was introduced into the filming tank, each of the experimental fishes aggressively suction-fed on the prey. Playing back the feeding films at a much slower rate than the 250 frames per second recording rate revealed some interesting behavioral differences between the two species when they captured prey. Lionfish approached the prey slowly, but, employed an explosive suction-feeding technique to rapidly capture the prey. In some films, cavitation, which was visible as streaks of bubbles in the vicinity of the lionfish mouth upon prey capture, was evident [61]. In contrast, the Mayan cichlid swam toward the prey upon introduction and suction fed on it, as described by Young [57]. These behavioral differences are confirmed in the subsequent MANCOVAR comparing the mean values of the kinematic variables between the two invasive fishes (Table 2).

The MANCOVAR revealed that prey-capture kinematics varied between species $\left(\mathrm{F}_{8,136}=5.545 ; \mathrm{P}=0.000\right)$, but, remained consistent across temperature $\left(\mathrm{F}_{15,136}=1.280 ; \mathrm{P}=\right.$ 0.218) (Table 3). Post-hocunivariate hypothesis tests revealed that maximum gape, time to maximum hyoid depression, maximum cranial rotation and time to maximum cranial rotation differed between the two species (Table 4). Prey-capture kinematics is invariant across temperature in both species (Table 5).

Table 2 shows the Mean and Standard Error of the Mean (S.E.M.) of the nine kinematic variables used to examine variation in feeding kinematics between species and across environmental temperature regimes.

Table 3 shows the results of the Two-Way Repeated Measures Multivariate Analysis of Covariance (MANCOVAR) on the nine kinematic variables used to examine variation in feeding kinematics between species and across environmental temperature regimes.

Table 4 shows results of the Post-MANCOVAR Hypothesis Test to determine the relative contribution of species-effect to the variation of prey-capture kinematics between species and across environmental temperature regimes.

Table 5 shows the results of the Post-MANCOVAR Hypothesis Test to determine the relative contribution of temperature-effect to the variation of prey-capture kinematics between species and across environmental temperature regimes.

Table 2. Mean and Standard Error of the Mean (S.E.M.) of kinematic variables.

\begin{tabular}{|c|c|c|c|}
\hline $\begin{array}{l}\text { Kinematic } \\
\text { Variable }\end{array}$ & $\begin{array}{l}20^{\circ} \mathrm{C} \\
\text { Mean } \pm \text { S.E.M. }\end{array}$ & $\begin{array}{l}25^{\circ} \mathrm{C} \\
\text { Mean } \pm \text { S.E.M. }\end{array}$ & $\begin{array}{l}30^{\circ} \mathrm{C} \\
\text { Mean } \pm \text { S.E.M. }\end{array}$ \\
\hline Maximum Gape (mm) & $\begin{array}{lc}M & 10.28 \pm 1.07 \\
L & 13.24 \pm 1.07\end{array}$ & $\begin{array}{ll}M & 10.12 \pm 1.07 \\
L & 11.35 \pm 107\end{array}$ & $\begin{array}{lr}\mathrm{M} & 8.83 \pm 1.07 \\
\mathrm{~L} & 12.39 \pm 1.07\end{array}$ \\
\hline Time to Maximum Gape & M $\quad 10.12 \pm 1.07$ & $0.18 \pm 1.17$ & $0.17 \pm 1.17$ \\
\hline
\end{tabular}




\begin{tabular}{|c|c|c|c|}
\hline $\begin{array}{l}\text { Kinematic } \\
\text { Variable } \\
\end{array}$ & $\begin{array}{l}0^{\circ} \mathrm{C} \\
\text { Mean } \pm \text { S.E.M. }\end{array}$ & $\begin{array}{l}5^{\circ} \mathrm{C} \\
\text { Mean } \pm \text { S.E.M. }\end{array}$ & $\begin{array}{l}3^{\circ} \mathrm{C} \\
\text { Mean } \pm \text { S.E.M. }\end{array}$ \\
\hline (ms) & $\begin{array}{ll}\mathrm{L} & 0.17 \pm 1.17\end{array}$ & $\begin{array}{ll}\mathrm{L} & 0.14 \pm 1.17\end{array}$ & $0.16 \pm 1.17$ \\
\hline Maximum Hyoid & M $\quad 3.86 \pm 1.11$ & M $\quad 3.72 \pm 1.11$ & M $\quad 4.28 \pm 1.11$ \\
\hline Depression (mm) & $4.70 \pm 1.11$ & $5.47 \pm 1.11$ & $5.21 \pm 1.11$ \\
\hline Time to Maximum Hyoid & M $\quad 0.39 \pm 1.26$ & M $\quad 0.31 \pm 1.26$ & M $\quad 0.22 \pm 1.26$ \\
\hline Depression (ms) & $\mathrm{L} \quad 0.12 \pm 1.26$ & $\mathrm{~L} \quad 0.10 \pm 1.26$ & $0.10 \pm 1.26$ \\
\hline Maximum Cranial & M $\quad 76.03 \pm 1.04$ & M $\quad 76.21 \pm 1.04$ & M $\quad 75.34 \pm 1.04$ \\
\hline Roatation (degree) & L $\quad 97.05 \pm 1.04$ & L $103.75 \pm 1.04$ & L $\quad 91.62 \pm 1.04$ \\
\hline Time to Maximum Cranial & M $\quad 0.39 \pm 1.22$ & M $\quad 0.27 \pm 1.22$ & M $\quad 0.23 \pm 1.22$ \\
\hline Rotation (ms) & $0.17 \pm 1.22$ & $0.15 \pm 1.22$ & $\mathrm{~L} \quad 0.19 \pm 1.22$ \\
\hline Maximum Lower Jaw & M $\quad 174.98 \pm 1.09$ & M $173.78 \pm 1.09$ & M $\quad 175.79 \pm 1.09$ \\
\hline $\begin{array}{l}\text { Angular Displacement } \\
\text { (degree) }\end{array}$ & L $\quad 177.83 \pm 1.09$ & L $140.60 \pm 1.09$ & L $\quad 174.5 \pm 1.09$ \\
\hline Time to Lower Jaw & $0.20 \pm 1.19$ & $0.21 \pm 1.19$ & M $\quad 0.17 \pm 1.19$ \\
\hline $\begin{array}{l}\text { Angular Displacement } \\
(\mathrm{ms})\end{array}$ & $0.25 \pm 1.19$ & $0.23 \pm 1.19$ & $0.18 \pm 1.19$ \\
\hline Feeding Duration (ms) & $\begin{array}{lc}\mathrm{M} & 0.64 \pm 1.15 \\
\mathrm{~L} & 0.59 \pm 1.15\end{array}$ & $\begin{array}{ll}\mathrm{M} & 0.52 \pm 1.15 \\
\mathrm{~L} & 0.45 \pm 1.15\end{array}$ & $\begin{array}{ll}\mathrm{M} & 0.48 \pm 1.15 \\
\mathrm{~L} & 0.48 \pm 1.15\end{array}$ \\
\hline
\end{tabular}

Table 3. Results of the Two-Way Repeated Measures Multivariate Analysis of Covariance (MANCOVAR).

\begin{tabular}{llllll}
\hline Source & SS & df & Mean Squares & F-Ratio & p-Value \\
\hline Kinematics Temperature & 0.185 & 16 & 0.012 & 1.280 & 0.218 \\
Kinematics Species & 0.108 & 16 & 0.007 & 0.751 & 0.737 \\
Kinematics Standard Length & 0.363 & 8 & 0.045 & 5.034 & 0.000 \\
Error & 1.225 & 136 & 0.009 & & \\
\hline
\end{tabular}

Table 4. Results of the Post-MANCOVAR Hypothesis Test.

\begin{tabular}{|c|c|c|c|c|c|}
\hline $\begin{array}{l}\text { Post-hoc for Species effect } \\
\text { Source }\end{array}$ & SS & df & Mean Squares & F-Ratio & p-Value \\
\hline Maximum Gape (mm) & 0.016 & 1 & 0.016 & 6.720 & 0.019 \\
\hline Error & 0.040 & 17 & 0.002 & & \\
\hline Time to Maximum Gape (ms) & 0.009 & 1 & 0.009 & 0.747 & 0.399 \\
\hline Error & 0.206 & 17 & 0.012 & & \\
\hline Maximum Hyoid Depression (mm) & 0.019 & 1 & 0.019 & 3.653 & 0.073 \\
\hline Error & 0.091 & 17 & 0.005 & & \\
\hline Time to Maximum Hyoid Depression (ms) & 0.285 & 1 & 0.285 & 10.582 & 0.005 \\
\hline Error & 0.458 & 17 & 0.027 & & \\
\hline Maximum Cranial Rotation (degree) & 0.018 & 1 & 0.018 & 23.31 & 0.000 \\
\hline Error & 0.013 & 17 & 0.001 & & \\
\hline Time to Maximum Cranial Rotation (ms) & 0.073 & 1 & 0.073 & 3.736 & 0.070 \\
\hline Error & 0.332 & 17 & 0.020 & & \\
\hline $\begin{array}{l}\text { Maximum Lower Jaw Angular } \\
\text { Displacement (degree) }\end{array}$ & 0.001 & 1 & 0.001 & 0.371 & 0.550 \\
\hline Error & 0.057 & 17 & 0.003 & & \\
\hline $\begin{array}{l}\text { Time to Maximum Lower Jaw Angular } \\
\text { Displacement (ms) }\end{array}$ & 0.005 & 1 & 0.005 & 0.346 & 0.564 \\
\hline Error & 0.259 & 17 & 0.015 & & \\
\hline Duration of Feeding & 0.002 & 1 & 0.002 & 0.182 & 0.675 \\
\hline Error & 0.162 & 17 & 0.010 & & \\
\hline
\end{tabular}

Table 5. Results of the Post-MANCOVAR Hypothesis Test.

\begin{tabular}{|c|c|c|c|c|c|}
\hline $\begin{array}{l}\text { Post-hoc for Temperature effect } \\
\text { Source }\end{array}$ & SS & df & Mean Squares & F-Ratio & p-Value \\
\hline Maximum Gape (mm) & 0.010 & 2 & 0.005 & 2.155 & 0.147 \\
\hline Error & 0.040 & 17 & 0.002 & & \\
\hline Time to Maximum Gape (ms) & 0.037 & 2 & 0.018 & 1.1516 & 0.248 \\
\hline Error & 0.206 & 17 & 0.012 & & \\
\hline Maximum Hyoid Depression (mm) & 0.008 & 2 & 0.004 & 0.78 & 0.474 \\
\hline Error & 0.091 & 17 & 0.005 & & \\
\hline Time to Maximum Hyoid Depression (ms) & 0.097 & 2 & 0.049 & 1.808 & 0.194 \\
\hline Error & 0.458 & 17 & 0.027 & & \\
\hline Maximum Cranial Rotation (degree) & 0.004 & 2 & 0.002 & 2.327 & 0.128 \\
\hline Error & 0.013 & 17 & 0.001 & & \\
\hline Time to Maximum Cranial Rotation (ms) & 0.032 & 2 & 0.016 & 0.818 & 0.458 \\
\hline Error & 0.332 & 17 & 0.020 & & \\
\hline
\end{tabular}




\begin{tabular}{|c|c|c|c|c|c|}
\hline $\begin{array}{l}\text { Post-hoc for Temperature effect } \\
\text { Source }\end{array}$ & SS & df & Mean Squares & F-Ratio & p-Value \\
\hline $\begin{array}{l}\text { Maximum Lower Jaw Angular Displacement } \\
\text { (degree) }\end{array}$ & 0.014 & 2 & 0.007 & 2.075 & 0.156 \\
\hline Error & 0.057 & 17 & 0.003 & & \\
\hline $\begin{array}{l}\text { Time to Maximum Lower Jaw Angular } \\
\text { Displacement (ms) }\end{array}$ & 0.067 & 2 & 0.033 & 2.185 & 0.143 \\
\hline Error & 0.259 & 17 & 0.015 & & \\
\hline Duration of Feeding & 0.060 & 2 & 0.030 & 3.15 & 0.069 \\
\hline Error & 0.162 & 17 & 0.010 & & \\
\hline
\end{tabular}
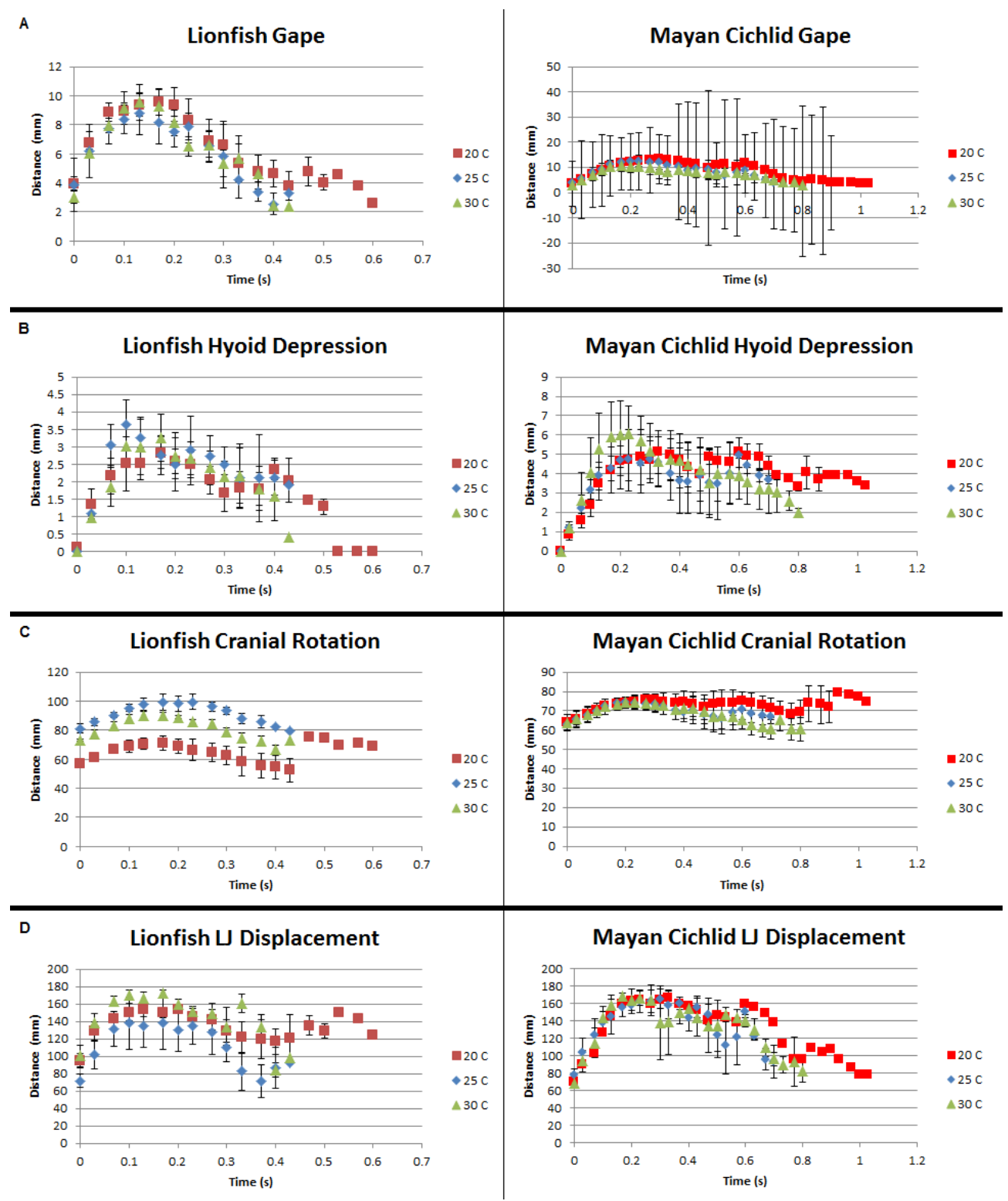

Figure 2. Kinematic profile comparing the time-course of each of the four kinematic-excursion variables in each species across environmentaltemperature regimes.

Figure 2 shows that the time course of each kinematicexcursion variable (i.e., kinematic profile) remains consistent for all water-temperature settings in both lionfish and Mayan cichlid.

\section{Discussion}

The urgent need to understand the consequences of the interaction between climate change and invasive species phenomena for population dynamics and community structure of native flora and fauna benefits from empirical data that demonstrate how organismal performance is affected by environmental change. One of the predicted impacts of climate change on the biology and ecology of exotic species is the northerly (or southerly) spread of tropical-invasive species, facilitated by the warming of the 
atmosphere and aquatic ecosystems in subtropical and temperate latitudes [62]. As poikilotherms, variations in the feeding performance and ecology of invasive fishes are expected to be consistent with predictions based on the known effects of temperature on the physiology and ecology of heterothermic, aquatic animals [63]. For example, the velocity of fin propulsion during swimming and mouth-opening during feeding, behaviors fueled by skeletal-muscle contraction and relaxation, are expected to double when ambient temperature is increased by $10^{\circ} \mathrm{C}$.This is because at the physiological level of analysis, there is a twofold increase in the rate of muscular contraction and relaxation for every $10^{\circ} \mathrm{C}$ increase in temperature [18-23]. At the ecological level of analysis, the food habit of some temperate fishes, such as largemouth bass, Micropterussalmoides, and pumpkinseed sunfish, Lepomisgibbosus, change seasonally, consistent with the seasonal cooling and warming of lakes or rivers in temperate ecosystems[64-66].

The highlight of this study is the persistent lack of temperature effects on the magnitude of kinematic excursion (e.g., peak gape), speed of cranial movement (e.g., time to peak gape) and the time course of jaw movements (e.g., gape profile) in the two contrasting models of invasive species reported here. A similar pattern of invariant feeding kinematics across temperature regimes was seen in another Florida invasive species, the pike killifish, Belonesoxbelizanus [35]. In all of these invasive species, the interspecific variation in feeding kinematics was consistent with species-specific differences in preycapture techniques employed to capture their primary food item. The pike killifish is a piscivorous specialist, with relatively long upper and lower jaws that are characteristic of ram-suction feeders $[67,68]$. The lionfish is an ambush predator, feeding primarily on fish prey [49]. The Mayan cichlid is a generalist predator, feeding on elusive fish and crustaceans, as well as non-elusive, relatively hard molluscs [57]. Notwithstanding this interspecific variation in feeding behavior, each species consistently utilized its optimal prey-capture kinematics in all environmentaltemperature regimes. More interestingly, the temperatureindependent feeding kinematics of these three Floridainvasive species is inconsistent with the findings of the only two other papers that reported the effects of temperature on feeding kinematics in fishes. The preycapture kinematics in both Florida-nativecentrachid fishes, bluegillLepomismicrochirus and largemouth bassMicropterussalmoides were affected by environmentaltemperature change [29,30]. Among other feedingkinematic variables that were affected by temperature, it took longer for fishes to reach peak gape in colder than in warmer temperatures[29,30]. Although not as high as predicted, the rate of gape change during prey-capture in these native fishes increased as water temperature dropped $10^{\circ} \mathrm{C}$ from ambient. This interesting contrast in the effects of temperature on feeding kinematics between invasive and native fishes in Florida inspires one to question, "Do sympatric nonnative and native species respond differently to environmental-temperature change?"

Species that adapt to a wide range of environmental biotic and abiotic factors that are introduced into ecosystems beyond their native distributions establish invasive populations at a faster rate than those species with narrow environmental tolerance [69-72]. Two tropical species, the lionfish $P$. volitans and the Mayan cichlid $C$. urophthalmus, are among the most dominant nonnative fish-species in the state of Florida [53,59]. Both species tolerate a wide range of environmental temperature and salinity conditions[54,73-76]. In addition, within the range of prey that each species could capture using the speciesspecific prey-capture mechanism and technique described previously, both fishes have plastic food habits and are capable of consuming novel prey available in the invasive habitats [68]. Thus, these nonnative fishes are well adapted to locally available prey resources; they are voracious, highly competitive predators in their invaded ecosystem $[42,46,51,52]$. The ability of lionfish and Mayan cichlid to respond positively to the biological and physical conditions in their invaded ecosystems allows them to continually expand their nonnative range of distribution, especially in Florida, USA.

Global-climate change in general and global-temperature change in particular has important consequences for the performance of invasive species because of (1) the temperature-induced effects on physiological and mechanical processes [63,77]; (2) the likelihood that these physiological effects extend to whole-organism performance [e.g., 29,30]; and (3) the resilience of invasive species and their resistance of whole-organism performance to temperature change [35,36, this study]. These plausible avenues where the interplay between climate-change and invasive-species phenomena may be demonstrated, need further investigation and confirmation.

\section{Acknowledgements}

The authors thank Lisa Young, Ben Compton, Kayla Chapman, Brian Bement, and MatthewSonnefeld for their assistance in filming lionfish and Mayan cichlid feeding behavior used in the kinematic analyses.

\section{References}

[1] M. R. Weinstein, M. Litt, D. A.Kertesz, P.Wyper, D. Rose, M. Coulter, A.McGreer, R.Facklam, C.Ostach, B. M. Willey, A.Borczyk, and D. E. Low, "Invasive infections due to a fish pathogen, Streptococusiniae. S. iniae study group,” N. Engl. J. Med.vol. 337, pp. 589-594. 1997.

[2] J. R. Britton, G. D. Davies, M. Brazier, and A. C. Pinder,"A case study on the population ecology of a topmouth gudgeon (Pseudorasboraparva) population in the UK and the implications for native fish communities,"Aquat.Conserv. vol. 17, pp. 749-759. 2006. 
[3] R. E. Gozlan, S. St-Hilaire, S. W. Feist, P. Martin, and M. L. Kent,"An emergent infectious disease threatens European fish biodiversity,"Nature. vol. 435, pp. 1046. 2005.

[4] L. B. Crowder, L. B, “Character displacement and habitat shift in a native cisco in Southeastern Lake Michigan: Evidence for competition?"Copeia. vol.4, pp. 878-883. 1984

[5] M. E. Douglas, P. C. Marsh, and W. L. Minckley, "Indigenous fishes of western North America and the hypothesis of competitive displacement: Medafulgida(Cyprinidae) as a case study,"Copeia. vol. 1, pp. 9-19. 1994.

[6] A. K. Singh, A. K.Pathak, and W. S. Lakra, "Invasion of an exotic fish - common carp, CyprinuscarpioL. in the Ganga River, India and its impacts,"ActaInchthyolPiscat. vol. 40, pp. 11-19. 2010.

[7] H. A. Mooney, and E. E. Cleland, "The evolutionary impact of invasive species,” PNAS. vol. 98,pp. 5446-5451. 2001.

[8] W. L. Perry, D. M. Lodge, and J. L. Feder, "Importance of hybridization between indigenous and nonindigenous freshwater species: an overlooked threat to North American biodiversity,’Syst. Biol. vol. 51, pp. 255-275. 2002.

[9] M. Sato, Y. Kawaguchi, J. Nakajima, T. Mukai, Y.Shimatani, and N. Onikura, "A review of the research on introduced freshwater fishes: new perspectives, the need for research, and management implications,".Landscap. Ecol. Eng. vol. 6, pp. 99-108. 2010

[10] W. W. Miley, "Ecological impact of the pike killifish, Belonesoxbelizanus, Kner, (Poeciliidae) in southern Florida," Thesis. Boca Raton (FL) Florida Atlantic University. 1978.

[11] R. Ogutu-Ohwayo, "The decline of the native fishes of lakes Victoria and Kyoga (East Africa) and the impact of introduced species, especially the Nile perch, Latesniloticus, and the Nile tilapia, Oreochromisniloticus."Environ. Biol. Fish. vol. 27,pp. 81-96. 1990.

[12] N. M. Bacheler, J. W. Neal, and R. L. Noble, "Diet overlap between native bigmouth sleepers (Gobiomorus dormitory) and introduced predatory fishes in a Puerto Rico reservoir,"Ecol.Freshw. Fish.vol. 13, pp 111-118.2004.

[13] M. L. McKinney, and J. L. Lockwood,"Biotic homogenization: a few winners replacing many losers in the next mass extinction,"Trends in Ecology \& Evolution. vol. 14, pp. 450- 453. 1999.

[14] F. J. Rahel, "Biogeographic barriers, connectivity and homogenization of freshwater faunas: it's a small world after all.’Freshwater Biology. vol. 52,pp. 696-710. 2007.

[15] M. B. Davis, and R. G. Shaw, "Range shifts and adaptive responses to Quaternary climate change,"Science. vol. 292, pp. 673-679. 2001.

[16] A. C. Baker, C. J.Starger, T. R. McClanahan, and P. W. Glynn, "Coral reefs: corals' adaptive response to climate change,"Nature.vol. 430, pp. 741. 2004.

[17] A. Charmantier, R. H. McCleery, L. R. Cole, C. Perrins, L. E. B. Kruuk, and B. C. Sheldon, "Adaptive phenotypic plasticity in response to climate change in a wild bird population,"Science.vol. 320,pp. 800-803. 2008.

[18] A. R. Cossins, and K. Bowler, Temperature biology of animals. New York, NY: Chapman and Hall (Methuen). 1987.
[19] A. Clarke, and N. M. Johnston, "Scaling of metabolic rate with body mass and temperature in teleost fish,"Journal of Animal Ecology. vol. 68 pp. 893-905. 1999.

[20] J. F. Gillooly, J. H. Brown, G. B. West, and V. M. Savage, "Effects of size and temperature on metabolic rate,"Science. vol. 293, pp. 2248-2251. 2001

[21] L. C. Rome, and A. A. Sosnicki, "The influence of temperature on mechanics of red muscle in carp," J. Physiol.vol. 427, pp. 151-169. 1990.

[22] R. K. Josephson, "Contraction dynamics and power output of skeletal muscle," Annual review of physiology. vol 55, pp. 527-546. 1993.

[23] S. Watabe, "Temperature plasticity of contractile proteins in fish muscle,"Journal of Experimental Biology.vol. 205 pp. 2231-2236. 2002.

[24] R. L. Malek, H. Sajadi, J. Abraham, M. A. Grundy, and G. S. Gerhard,"The effects of temperature reduction on gene expression and oxidative stress in skeletal muscle from adult zebrafish,"Comparative Biochemistry and Physiology Part C: Toxicology \& Pharmacology. vol. 138, pp. 363-373. 2004.

[25] L. C. Rome, D. M. Swank, and D. J. Coughlin, "The influence of temperature on power production during swimming.II. Mechanics of red muscle fibers in vivo,"J. Exp. Biol.vol. 203, pp. 333-345. 2000.

[26] I. Herbing, "Effects of temperature on larval fish swimming performance: the importance of physics to physiology,"Journal of Fish Biology. vol. 61, pp. 865-876. 2002.

[27] C. G. Lee, A. P. Farrell, A. Lotto, M. J.MacNutt, S. G.Hinch, and M. C. Healey, "The effect of temperature on swimming performance and oxygen consumption in adult sockeye (Oncorhynchusnerka) and coho (O. kisutch) salmon stocks,'Journal of Experimental Biologyvol. 206, pp. 32393251. 2003

[28] B. S. Green, and R. Fisher, "Temperature influences swimming speed, growth and larval duration in coral reef fish larvae,"Journal of Experimental Marine Biology and Ecology. vol. 299, pp. 115-132. 2004.

[29] A. P. Wintzer, and P. J. Motta, "The effects of temperature on prey-capture kinematics of the bluegill (Lepomismacrochirus): implications for feeding studies,”Can. J. Zool.vol. 82, pp. 794-799. 2004

[30] M. S. DeVries, and P. C. Wainwright, "The effects of acute temperature change on prey capture kinematics in largemouth bass, Micropterussalmoides."Copeia. vol. 3, pp. 437- 444. 2006.

[31] P. L. Shafland, and J. M. Pestrak, "Lower lethal temperatures for fourteen nonnative fishes in Florida,'Enviro. Biol. of Fish. vol. 7, pp. 149-156. 1982.

[32] Invasive Species Advisory Committee. Invasive Species and

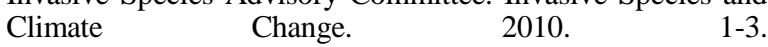
Available:http://www.invasivespecies.gov/ISAC/White\%20Pa pers/Climate_Change_White_Paper_FINAL_VERSION.pdf

[33] A. L. Smith, N. Hewitt, N. Klenk, D. R. Bazely, N. Yan, S. Wood, I. Henriques, J. I. MacLellan, and C. Lipsig-Mumme, "Effects of climate change on the distribution of invasive alien species in Canada: a knowledge synthesis of range change projections in a warming world," Environ. Rev.vol. 20, pp. 1-16.2012. 
[34] K. A. Dickson, J. M. Donley, C. Sepulveda, and L. Bhoopat, "Effects of temperature on sustained swimming performance and swimming kinematics of the chub mackerel Scomberjaponicus," J. Exp. Biol. vol. 205, pp. 969-980, 2002.

[35] T. J. Sloan, and R. G. Turingan,"Invariant feeding kinematics of two trophically distinct invasive Florida fishes, Belonesoxbelizanus and Cichlasoma urophthalmus across environmental temperature regimes," International Journal of Biology. vol. 4, pp. 117-126.2012.

[36] R. G. Turingan, and T. J. Sloan, "Modeling the relationship between environmental temperature and feeding performance in Florida (USA) nonnative fishes, with implications for invasive-species response to climate change," Annual Review \& Research in Biology. In press. 2013.

[37] C. C. Coutant, "Compilation of temperature preference data," Journal of the Fisheries Research Board of Canada. vol. 34, pp. 739-745, 1977.

[38] I. Dey, C. Buda, T. Wiik, J. E. Halver, and T. Farkas, "Molecular and structural composition of phospholipid membrane in livers of marine and freshwater fish in relation to temperature," PNAS. vol. 90, pp. 7498-7502, 1993.

[39] E. D. Houde, "Differences between marine and freshwater fish larvae: implications for recruitment," ICES J. Mar. Sci. vol. 51, pp. 91-97. 1994.

[40] P. E. Whitfield, T. Gardner, S. P. Vives, M. R. Gilligan, W. R. Courtenay, G. C. Ray, and J. A. Hare, "Biological invasion of the Indo-Pacific lionfish Pteroisvolitans along the Atlantic coast of North America," MEPS. vol. 235, pp. 289297. 2002.

[41] R. M. Hamner, D. W. Freshwater, and P. E. Whitfield, "Mitochondrial cytochrome $b$ analysis reveals two invasive lionfish species with strong founder effects in the western Atlantic," Journal of Fish Biology. vol. 71, pp. 214-222. 2007.

[42] J. A. Morris and J. L. Akins, "Feeding ecology of invasive lionfish (Pteroisvolitans) in the Bahamian archipelago," Environmental Biology of Fishes. vol. 86, pp. 389-398. 2009.

[43] J. A. Morris and P. E. Whitfield, "Biology, ecology, control," NOAA Technical Memorandum NOS-NCCOS. vol. 99. 2009.

[44] J. A. Hare and P. E. Whitfield, "An integrated assessment of the introduction of lionfish (Pteroisvolitans/miles complex) to the western Atlantic Ocean," NOAA Technical Memorandum NOS NCCOS. vol. 2. 2003.

[45] P. E. Whitfield, J. A. Hare, A. W. David, S. L. Harter, R. C. Munoz, and C. M. Addison, "Abundance estimates of the Indo-Pacific lionfish Pteroisvolitans/miles complex in the western North Atlantic," NOAA Technical Memorandum NOS NCCOS. vol. 9, pp. 53-64. 2007.

[46] M. A. Albins and M. A. Hixon, "Invasive Indo-Pacific lionfish Pteroisvolitansreduce recruitment of Atlantic coralreef fishes," Marine Ecology Progress Series. vol. 367, pp. 233-238. 2008

[47] W. R. Courtenay, "Marine fish introductions in south-eatern Florida," American Fisheries Society Introduced Fish
Section Newsletter. vol. 14, pp. 2-3. 1995.

[48] C. A. Layman and J. E. Allegier, "Characterizing trophic ecology of generalist consumers: a case study of the invasive lionfish in the Bahamas," Marine Ecology Progress Series. vol. 448, pp. 131-141. 2012.

[49] J. A. Pfeiffenberger, "Modulation and scaling of prey capture kinematics through ontogeny in invasive IndoPacific lionfish, Pteroisvolitans/miles complex," Thesis. Florida Institute of Technology. 2012.

[50] R. R. Miller, "Geographical distribution of Central American freshwater fishes," Copeiavol. 1966, pp. 773-802. 1966.

[51] A. Vaslet, C. France, C. C. Baldwin, and I. C. Feller, "Dietary habits of juveniles of the Mayan cichlid, Cichlasoma urophthalmus, in mangrove ponds of an offshore islet in Belize, Central America," Neotropical Ichthyology. vol. 10, pp. 667-674. 2012.

[52] G. T. Bergmann, and P. J. Motta, "Diet and morphology through ontogeny of the nonindigenous Mayan cichlid 'Cichlasoma (Nandopsis)' urophthalmus (Günther 1862) in southern Florida," Environmental Biology of Fishes.vol. 72, pp. 205-211. 2005.

[53] Florida Wildlife Commission. Accessed December 2012. Available at: http://myfwc.com/.

[54] C. A. Martinez-Palacios, L. G. Ross, and M. RosadoVallado, "The effects of salinity on the survival and growth of juvenile Cichlasoma urophthalmus,"Aquaculture. vol. 91 pp. 65-75. 1990.

[55] R. Chavez-Lopez, M. S. Peterson, N. Brown-Peterson, A. A. Morales-Gomez, and J. Franco-Lopez, "Ecology of the Mayan cichlid, Cichlasoma urophthalmus, in the Alvarado Lagoonal system, Veracruz, Mexico,"Gulf and Caribbean Res.vol. 17,pp. 123-131. 2005.

[56] C. J. Hellig, M.Kerschbaumer, K. M.Sefc, and Koblmüller,"Allometric shape change of the lower pharyngeal jaw correlates with a dietary shift to piscivory in a cichlid fish,'Naturwissenschaften. vol.97, pp. 663-672. 2010 .

[57] L. E. Young, "Variation in feeding ecomorphology between northern and southern Florida subpopulations of the invasive Mayan cichlid, Cichlasoma urophthalmus,"Thesis. Florida Institute of Technology. .2011.

[58] C. D. Hulsey, "Function of a key morphological innovation: fusion of the cichlid pharyngeal jaw,"Proceedings of the Royal Society B. vol. 273, pp. 669-675. 2006.

[59] R. Anderson, "Geographic variation and aspects of the life history of BelonesoxbelizanusKner (Pisces: Poeciliidae) from Central America,” Thesis. 1980.

[60] National Oceanic and Atmospheric Administration. National Oceanographic Data Center. Accessed December 2012.Available http://www.nodc.noaa.gov/dsdt/cwtg/all.html.

[61] R. G. Turingan and P. C. Wainwright, "Morphological and functional bases of durophagy in the queen triggerfish, Balistesvetula (Pisces, tetraodontiformes)," Journal of Morphology. vol. 215, pp. 101-118. 1993. 
[62] F. J. Rahel and J. D. Olden, "Assessing the effects of climate change on aquatic invasive species," Conservation Biology. vol. 22 pp. 521-533. 2008 .

[63] P. W. Hochachkaand G. N. Somero,"Biochemical Adaptation: Mechanisms and Processes in Physiological Evolution”Oxford, UK: Oxford University Press. 2002.

[64] P. A. Cochran and I. R. Adelman, "Seasonal aspects of daily ration and diet of largemouth bass, Micropterussalmoides, with an evaluation of gastric evacuation rates," Environmental Biology of Fishes. vol. 7, pp. 265-275. 1982.

[65] S. M. Adams, R. B. McLean, and J. A. Parrotta, "Energy partitioning in largemouth bass under conditions of seasonality of seasonally fluctuating prey availability," Transactions of the American Fisheries Society. vol. 111, pp. 549-558. 1982

[66] E. Garcia-Berthou and R. Moreno-Amich, "Food of introduced pumpkinseed sunfish: ontogenetic diet shift and seasonal variation," Journal of Fish Biology. vol. 57, pp. 2940. 2000.

[67] C. A. Harms, "Feeding versatility of the invasive pike killifish, Belonesoxbelizanus (Cyprinofontiformes: Poeciliidae). Thesis. Florida Institute of Technology. 2011.

[68] C. A. Harms and R. G. Turingan, "Dietary flexibility despite behavioral stereotypy contributes to successful invasion of the pike killifish, Belonesoxbelizanus, in Florida, USA," Aquatic Invasions. vol. 7, pp. 547-553. 2012.

[69] A. H. Arlington, and D. S. Mitchell, "Aquatic invading species. In: Groves, R.H., J.J. Burdon (Eds.), Ecology of Biological Invasions," Cambridge University Press, New York, NY. pp. 34-53. 1986.

[70] F. diCastri, "On invading species and invaded ecosystems: the interplay of historical chance and biological necessity," In di Castri, F., A.J. Hansen and M. deBussche (Eds.), Biological Invasions in Europe and the Mediterranean Basin.Kluwer Academic Publishers, Boston, MA. pp. 3-16. 1990.

[71] A. K. Sakai, F. W.Allendorf, J. S. Holt, D. M. Lodge,J. Molofsky, K. A. With,...S. G. Weller, "The population biology of invasive species,"Annual Review of Ecology and Systematics. vol. 32, pp. 305-332. 2001.

[72] C. E. Lee,"Evolutionary genetics of invasive species," Trends in Ecology \& Evolution. vol.17, pp. 386-391. 2002.

[73] J. R. Stauffer, and S. E.Boltz, "Effect of salinity on the temperature preference and tolerance of age-0 Mayan cichlids,"Transactions of the American Fisheries Society. vol. 123 pp. 101-107. 1994.

[74] M. E. Kimball, J. M. Miller, P. E. Whitfield, and J. A. Hare, "Thermal tolerance and potential distribution of invasive lionfish (Pteroisvolitans/miles complex) on the east coast of the United States,'Mar. Ecol. Prog. Ser. vol. 283,pp. 269278. 2004.

[75] P. J. Schofield, W. F. Loftus, and J. A. Fontaine, "Salinity effects on behavioural response to hypoxia in the non-native Mayan cichlid Cichlasoma urophthalmus from Florida Everglades wetlands,'Journal of Fish Biologyvol. 7, pp. 149-156. 2009.

[76] Z. R. Jud, C. A. Layman, J. A. Lee, and D. A. Arrington, "Recent invasion of a Florida (USA) estuarine system by lionfish Pteroisvolitans / P. miles,"Aquat. Biol. vol. 13, pp. 21-26. 2011.

[77] S. Vogel, "Life in Moving Fluids, the Physical Biology of Flow, $2^{\text {nd }}$ edn," Princeton University Press, Princeton, NJ, pp. 467. 1994. 